\title{
Organizational Core Issues and Strategy Implementation in Public Tertiary Institutions in Nigeria
}

\author{
Michael P. Nnamseh, Ph. D*, Victor A. Umoh, Ph.D \\ Department of Business Management, University of Uyo, Uyo, Nigeria
}

DOI: $10.36348 /$ SJBMS.2019.v04i12.002

| Received: 20.11.2019 | Accepted: 27.11.2019 | Published: 10.12.2019

*Corresponding author: Michael P. Nnamseh

\section{Abstract}

This study focused on organizational core issues and strategic implementation in public tertiary institutions in Nigeria. A survey research design was adopted with mixed instruments of questionnaire and interview; primary data were gathered through the administration of 94 copies of the questionnaire instrument combined with in-depth interviews with 6 administrators of the studied organizations; purposive sampling was used for data collection. Descriptive analytical tools were used to analyze data profile. Inferential statistics, correlation analysis and multiple regression analysis were used to test research hypothesis. The results revealed that the application of strategic management by these institutions is still at its infancy. The study also revealed that organizational issues, namely leadership (Beta=.301, $\mathrm{t}=3.071, \mathrm{p}<0.05$ ) organizational structure $(\mathrm{Beta}=.213, \mathrm{t}=2.766, \mathrm{p}<0.05)$, organizational culture $(\mathrm{Beta}=.323, \mathrm{t}=3.845, \mathrm{p}<0.05)$ and resource allocation $(\mathrm{Beta}=.233, \mathrm{t}=2.427, \mathrm{p}<0.05)$ had significant positive influence on strategic implementation in public tertiary institutions in Nigeria. It was recommended that managements of public tertiary institutions in Nigeria should benchmark the strategic management practices of their peers in the developed economy in guiding their administration; that the capacity of administrators of these institutions be strengthened through relevant exposure and training in strategic management; that in view of the significant positive influence of organizational issues on strategic implementation, these variables should be properly managed to achieve comparative advantage.

Keywords: Strategy Implementation, Leadership, Organizational Culture, Organizational Structure, Resource Allocation, Public Tertiary Institutions, Nigeria.

Copyright @ 2019: This is an open-access article distributed under the terms of the Creative Commons Attribution license which permits unrestricted use, distribution, and reproduction in any medium for non-commercial use (NonCommercial, or CC-BY-NC) provided the original author and source are credited.

\section{INTRODUCTION}

Contemporary operating environment of organizations which is characterized by turbulence and uncertainty requires organizations to engage in managerial decisions and actions that focus more on long-term performance and survival of these concerns. This calls for the application of strategic management techniques. 'Strategic Management' is the term used to explain the management of strategy which is considered a tool for achieving and sustaining organizational success. It describes practices by organizations such as strategy formulation, strategy implementation and strategic evaluation and control. Strategy formulation is concerned with developing a number of strategies and evaluating them with a view to making a choice. Strategy implementation as described by Makpere,
Mavhiki, Nyamwanza, Sikomwe and Mhonde [22] is the course of action that converts organizational intentions into actions and makes certain such intentions are carried out in order to realize goals already specified. Strategic control, involves monitoring activities and performance in relation to implementation of chosen strategy and taking corrective actions where necessary. Of these three elements, strategy implementation is considered the most difficult.

Across different sectors, strategic management has been embraced because of its perceived contribution to organizational effectiveness [36]. The challenge, however, is the rather dismal performance of strategies in various settings partly due to poor implementation. However, in the strategic management literature, a number of variables are mentioned as having a bearing 
Michael P. Nnamseh \& Victor A. Umoh; Saudi J Bus Manag Stud, Dec., 2019; 4(12): 868-877

on strategy implementation. These factors include leadership style, organizational structure, organizational culture, organizational resources, technology, information availability among others. Most authors agree that these factors influence strategy implementation and that each factor's impact is at a different level and carries a different force, an indication that the variables should be given a prime place in strategic management efforts.

The major aim of strategic management is to offer directional signals to the organization such that it eases its ability to realize its goals and at the same time respond to the opportunities and threats carried by operational environment [29]. It is important that organizational issues and actions of entities are properly managed to facilitate successful implementation of strategies. As noted by Raps [31], strategy implementation is important to institutional performance because strategies do not add value unless properly implemented.

In Nigeria, tertiary education, as highlighted in the National Policy on Education [11], among others is aimed at:

- Adding value to national development by way of training high level manpower

- Developing and instilling in the citizens and nation proper values

- $\quad$ Building up citizens capacity to of individuals to know their environments

- Imparting self-reliant skills to citizens

- Advancing scholarship and community service in individuals

- Creating unity among various sections of the nation

- Helping the course of knowledge on issues both national and international

In an attempt at addressing challenges facing the country's education sector, the Federal Ministry of Education developed a 4-year strategic plan covering the period 2011-2015. This strategic plan identified key turn around strategies aimed at making immediate and long-term impact in the education sector in six focal areas. The first two, access and equity; standard and quality assurance, are the basic strategic goals of the education sector. The remaining four, strengthening institutional management; teacher education and development; technical and vocational education and training; and funding, partnerships resource mobilization and utilization are issues that must be addressed in order to achieve the basic goals. While efforts are being put in place to improve the country's educational sector through strategy implementation, the influence of core organizational issues on strategic implementation success requires a thorough examination. In this regard, issues such as leadership, organizational structure, organizational culture and resource allocation would have to be investigated to establish their managerial implications and influence on strategy implementation success. A study of these issues would provide useful insights that can bolster up strategic management efforts of public tertiary institutions in Nigeria.

\section{RESEARCH OBJECTIVES}

The general objective of this study was to investigate the influence of organizational issues on strategy implementation success in public tertiary educational institutions in Nigeria.

The specific objectives were:

- To investigate the influence of leadership on strategy implementation success in pubic tertiary institutions in Nigeria

- To ascertain the impact of organizational structure on strategy implementation success in pubic tertiary institutions in Nigeria

- To examine the effect of organizational culture on strategy implementation success in pubic tertiary institutions in Nigeria

- To explore the influence of resource allocation on strategy implementation success in pubic tertiary institutions in Nigeria

\section{RESEARCH HYPOTHESIS}

The following hypotheses were formulated for this study:

- There is no significant relationship between leadership and strategy implementation success in pubic tertiary institutions in Nigeria

- There is no significant relationship between organizational structure and strategy implementation success in pubic tertiary institutions in Nigeria

- There is no significant relationship between organizational culture and strategy implementation success in pubic tertiary institutions in Nigeria

- There is no significant relationship between resource allocation and strategy implementation success in pubic tertiary institutions in Nigeria

\section{REVIEW OF RELATED LITERATURE Conceptual Framework}

Strategic Management provides a forwardlooking view and indicates the path between where the organization is and its vision for the future. It makes an attempt at organizing information in a way that allows effective decisions to be made under conditions of uncertainty, implying organizations should avoid maintaining a single strategy for use in their operations [29]. As noted by Johnson, Scholes and Whittington [17], strategic management creates knowledge on the strategic position of the organization, making strategic choices for the future and managing strategy so formulated. Wheelen and Hunger [38] see concerns of 
strategic management as those of strategy formulation, strategy implementation and control.

The strategic management literature encourages organizations to embrace and employ the concept .The argument being that strategizing provides an enterprise with a game plan for use in their activities; also, it enables an organization to match its capabilities and competencies to various developments in the environment [8]. Henry [14] describes strategic management as involving strategy analysis, strategy formulation and strategy implementation. In the view of Toma [37], strategic management is the formulation, implementation and evaluation of counter- functional decisions which make it possible for an organization to achieve its goals.

\section{Strategic Management Process \\ Strategy Formulation}

Strategy formulation results from strategic analysis which entails examining an organization's goal, its suitability and viability to the organization and identifying issues that need to be dealt with through scanning both internal and external environments of the business for their strengths and weaknesses and opportunities and threats respectively. Managers are expected to utilize information obtained in strategy analysis regarding the organization and its environment to define the organization's mission, objectives, strategies and policies. Thomson, Strickland and Gamble [36] see strategy formulation as entailing answering a series of hows: how to grow the business; how to please the customer; how to outcompete rivals.

\section{Strategy Implementation}

Strategy implementation involves translating strategies already formulated into action. Strategy implementation involves the management of all other internal elements within an organization to ensure strategy implementation success [39]. It is concerned with putting in place yearly objectives, programs, budgets and procedures in order to achieve successful implementation [9].

\section{Strategy Evaluation and Control}

David [9] describes strategy evaluation as the final stage of strategic management. Strategy evaluation provides information on the performance of a strategy (gies).It makes for a comparison between formulated strategy and performance; it also provides feedback for corrective actions to be taken where necessary [39]. Strategy evaluation and control work together to ensure that organizations are achieving their formulated strategies. According to David [9], strategy evaluation involves three activities, namely:

- Reviewing both external and internal factors which serve as the bases for current strategies

- Measurement of strategy performance

- Effecting corrective actions

\section{Leadership and Strategy Implementation}

A major function of leadership is that of influencing employees' behavior in order to accomplish the organizational goals. In the strategic management process, leadership is expected to play its role effectively. Crittenden and Crittenden [7] argue for leaders that have the ability, those with the requisite exposure and those that are knowledgeable in the task of implementing strategies. Mehra, Smith, Dixon and Roberts [24] see organizational leaders that are clever as going beyond inspiring organizational members' ability to bring about better management and results; leadership that satisfies the employees' yearnings and expectations while driving the process of actualizing the goals and objectives of the organization.

\section{Organizational Structure and Strategy Implementation}

Organizational structure can be seen as an arrangement of tasks and sub-tasks required to aid the implementation of strategy [19]. Structure in this perspective defines three components viz specification of groupings of individuals into departments, formal relationships and hierarchical levels and the system of effective communication, co-ordination and integration. Chandler [4] sees organizational structure as the way an organization is designed for ease of management. For him, organizational design has two aspects: lines of authority and communication; and information and data. He observes that there is a need for building an internal organization structure that is responsive to the needs of the strategy. He argues that structure follows strategy and that there should be a fit between strategy and organizational structure for successful strategy implementation. Hill and Jones [15] added that with increased difficulty of organizational structure, more will be needed in terms of staff supervision, integration of units and their functions to make for proper functioning of the structure in place.

\section{Organizational Culture and Strategy Implementation}

According to Bushardt, Glascoff, and Doty [3], organizational culture can assist or undermine strategy implementation by gaining commitment and efforts from organizational members. Schein [33] sees organizational culture as a pattern of shared basic belief learned by the organization while attending to its external and internal issues and also transferred to new organizational members as current way of doing things.

Charan [5] stresses the importance of culture by stating that the greatest cause of corporate under performance is the failure to execute and the inability to take decisive action is rooted in a company's culture. Organizational culture is a vital element in strategy implementation since it affects the way employees do things in the organization [ 39 ]. 


\section{Resource Allocation and Strategy Implementation}

Resources are the most critical elements in organizational life. Its inadequacy or inappropriate mix and utilization may result in objective summersault. Thompson, Gamble and Strickland [36] collaborating this position observed that not having enough resources to implement its strategies might result in achieving objectives partly or not achieving at all. Kandie and Koech (18) reason that for effective strategy implementation to be achieved, all the necessary resources such as time, finance, skills and knowledge must be available.
Henry [14] categorizes resources into physical resources, financial resources and human resource. Allio [1] believes that these resources-financial, personnel and time should be incorporated in the company's financial plan from outset. Pryor, Anderson, Toombs and Humphreys [30] see management's challenge to be that of allocating resources to important activities and co-ordinating organizational functions and staff.

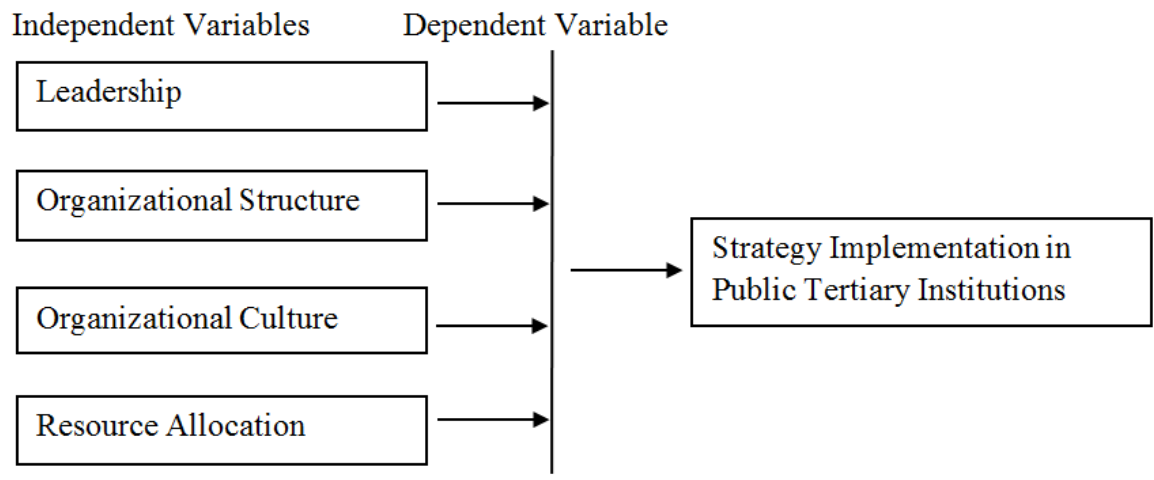

Fig-1: Conceptual Framework

Source: Authors' Conceptualization, 2019

\section{THEORETICAL FOUNDATION}

This study is primarily anchored on Systems theory. The systems theory is based on the ideas developed in general systems theory by Von Bertalanffy in the 1950s. It emphasizes the importance of aligning different parts of the organization. The idea behind systems theory is that organizations cannot function as isolated entities or independently. Systems theory deals with problems, relationships and inter-dependence. It reinforces alignment of various parts of the organization and organizational issues in strategic management efforts. Organizational issues such as leadership, structure, culture and resource allocation are interlinked parts. These issues influence one another. They are supposed to work in coherence for the successful management of strategy by organizations; these variables may determine to an extent the way strategy is formulated and implemented. Further, strategy formulation stage, addresses among other things, how implementation will be carried out; strategy implementation stage, provides performance data for evaluation and control; strategy evaluation and control stage, generates useful inputs for future strategy formulation. Strategic management according to the systems theory lacks behind where there is improper alignment. Thus for strategy management to be successful, alignment of organizational issues and strategic management practices should be given serious attention.

Strategic management is an organizational issue. It is a complex task carried out in an organization, a complex system, compost of variables and stakeholders that should be properly aligned. Tertiary educational institutions are open systems, they are part of the larger system and their survival and growth depend to a large extent on its linkages and interactions with other components within and outside its environment. The systems perspective therefore become a balanced fit in situating this study.

\section{EMPIRICAL REVIEW}

Mapetere, Mavhiki, Nyamwanza, Mhonde [22] investigated the role of leadership in strategy implementation in Zimbabwe state -owned enterprises. The study was a survey and involved 7 top managers, 14 middle managers and 167 employees who made up its respondents of 188 selected randomly from four state-owned enterprises. Data were collected through questionnaire and interview; method of data analysis was descriptive statistics. The study revealed that low leadership involvement results in partial success in strategy implementation. It concluded that for successful strategy implementation to be achieved, leadership should be able to craft a vision for any strategic initiative, design an effective communication structure as well as role model behavior necessary for implantation success.

Koech and Namusonge [21] carried out a research on the effect of leadership styles on performance at state corporations in Kenya. It was a survey of thirty (30) state-owned corporations in Mombasa. Questionnaire was administered to 
Michael P. Nnamseh \& Victor A. Umoh; Saudi J Bus Manag Stud, Dec., 2019; 4(12): 868-877

respondents. Laissez-faire; transactional; and transformational leadership styles were used as independent variables. The dependent variable was represented by organizational performance. Correlation analysis was employed. The study showed high correlations between transformational-leadership factors and organizational performance and low correlations between the transactional-leadership behaviors and organizational performance. Laissez-faire leadership style was found to be not significantly correlated to organizational performance.

George and Wagoki [12] investigated the effects of formal institutional structure on strategic plan implementation in public secondary schools in Bahati Sub-County, Kenya. The study was a survey. Structured questionnaire were administered to respondents. The study's population was derived from 31 public secondary schools' principals in Bahati region. Findings from the study indicated that increased formalization fail in strategy implementation.

Atieno [2] examined the influence of centralized structure on implementation of strategies by County Government of Nakuru, Kenya. The aim of the study was to establish how organizational structure, affects implementation of strategies by County Governments. The research used descriptive design and did a census on 46 heads of departments and sections drawn from all government departments, whose functions have been devolved. Questionnaire served as instrument for collecting data from the respondents. The findings indicate that there is an average positive significant relationship between centralization and strategy Implementation.

Isaboke [16] conducted a study on the influence of organizational culture on implementation of strategies in selected Kenyan Universities. With a target population of 1,026 employees in the chosen institutions, the researcher selected a sample of 103.the study used a survey design and by way of proportionate stratified sampling method administered copies of questionnaire on the respondents. Outcome of the study indicated that organizational culture had an influence on strategy implementation in institutions of higher learning.

Nawaser, Shahmehr, Kamel and Vesal [26] assessed the relationship between strategy and organizational culture in the Manufacturing Industry of Iran. The case organization was Iran-Khodro Automotive Company located in Tehran. The research was a survey with target population of 320 and 175 as sample size. Questionnaire was administered on employees of the company who served as respondents. The study established a significant relationship between strategy and organizational culture.
Mango [23] studied determinants of successful strategy implementation among selected public schools in South Africa. Variables considered were resource allocation, compensation management, managerial behavior and institutional policies. Using simple random sampling technique, a total of one hundred and sixty-five respondents were chosen to participate in the survey. A questionnaire structured within a Likert scale format was used. Results of the study indicated that resource allocation, compensation management, managerial behaviour, and institutional policies had statistically significant association with successful strategy implementation.

Kevogo and Waiganjo [20] studied the factors influencing implementation of strategic plans in public secondary schools in Kenya. This study aimed at determining the influence of resource allocation and organizational structure on implementation of strategic plans in public secondary schools. Survey was carried out on the 17 public secondary schools in Thika West Sub-County in Kiambu County which formed its population. Stratified random sampling was used. Eighty respondents took part in the study with data collected through questionnaire, interview schedules and observation. Data was treated through means, questionnaire, frequencies and percentages. The study revealed that resource allocation contributed the most to the implementation of strategic plans; followed by organizational structure.

\section{RESEARCH METHODOLOGY Research Design}

This study employs a survey research design with mixed instruments of questionnaire and interview guide for primary data collection. The study's population comprised school administrators and academic staff of public tertiary educational institutions in Akwa Ibom State of Nigeria from the position of heads of departments, directors of colleges/schools, deans of faculties to chief executives. As at December, 2018, official staff data obtained from the institutions under study in the mentioned categories indicated a total of 94 as target population. In view of the fact that the population was not large, a census study was carried out using purposive sampling technique in gathering data as only staff with managerial responsibilities were involved. Descriptive analytical tools namely, frequency counts and percentages were used to analyze data profile. Inferential statistics such as correlation analysis and multiple regression analysis were used to test hypotheses. The research instrument was pre-tested in a pilot study. Further, Cronbach's Alpha was used to test the reliability of the instrument; this was facilitated using the Statistical Package for Social Science (SPSS). Cronbach's Alpha coefficient of 0.7 and above qualifies an instrument as reliable [34]. Results of the reliability tests presented below imply that the scales measuring the variables had a very high reliability; accordingly, the instrument was considered reliable for the study. 
Table-1: Reliability test of instrument

\begin{tabular}{|l|l|l|}
\hline Variables & Cronbach's Alpha & No. of Items \\
\hline Leadership and Strategy Implementation & 0.71 & 9 \\
\hline Organizational Structure and Strategy Implementation & 0.78 & 9 \\
\hline Organizational culture and Strategy Implementation & 0.79 & 9 \\
\hline Resources allocation and Strategy Implementation & 0.81 & 9 \\
\hline
\end{tabular}

\section{Techniques of Data Analysis Model Specification}

Following a review of extant literature which seems to indicate various forms of relationships between the study's independent variables and the dependent variable, the sensed relationship was translated into multiple regression for purpose of analysis.

The multiple regression equation is given as: $\mathrm{Y}=\beta 0+\beta 1 \mathrm{X} 1+\beta 2 \mathrm{X} 2+\beta 3 \mathrm{X} 3+\beta 4 \mathrm{X} 4+\mathrm{E}$

Where,

\author{
$\mathrm{Y}=$ Strategy Implementation in State-owned \\ Tertiary Institutions \\ X1 = Leadership \\ $\mathrm{X} 2$ =Organizational Structure \\ X3 = Organizational Culture \\ X4 = Resources Allocation \\ $\mathrm{E}=$ Error Term \\ $\mathrm{B} 0=$ Constant Term \\ B1, B2, B3, B4 = Beta Co-efficien
}

\section{DATA PRESENTATION AND ANALYSIS} Strategic Management Practices at Akwa Ibom State College Of Education, Afaha Nsit

During in-depth interviews held with selected management staff of the college responsible for strategic planning, details of strategy formulation, strategy implementation and strategy evaluation and control of the college were given as follows:

\section{Strategy Formulation}

The Strategic Management Committee (SPC) is constituted by the Provost and is headed by the Deputy Provost Administration. Members of the committee include Deputy Provost Academics, Deans of Schools, Directors of Programmes and Head, Academic Planning. The committee was sponsored to attend a training programme in strategic management outside the college. Stakeholder groups such as students and alumni are not represented in the committee. The committee meets for several weeks, brainstorms and comes up with a comprehensive strategic plan for the college. This is presented to the Academic Board for rectification. The first strategic plan of the college was that of 2005-2009.The school has a 5-year planning cycle, a tradition of developing its strategic plan to coincide with programmes' accreditation by its regulator, National Commission for Colleges of Education (NCCE). Accreditation of academic programmes in the school takes place every five years.
The college's plan is also influenced by government policy as directed by the Ministry of Education.

\section{Strategy Implementation}

The implementation of the college's formulated educational strategies is largely decentralized. Deans are to deliver on their schools programs and plans while concerned departments are also involved in implementation. At the corporate level, congregation is used by management to update members on what the school is doing viz-a-viz its plan. At the school and departmental levels, statutory board meetings are used. The Quality Assurance Unit within the directorate of academic planning has the responsibility to monitor implementation of programmes in the school. A unique feature in the implementation of the college's academic programmes is its reliance on 'minimum standard', a document issued by NCCE and which serves as benchmark for programmes offered by all colleges of education in Nigeria.

\section{Strategy Evaluation and Control}

Strategy evaluation and control in the college is the responsibility of the SPC. Tools used are reports sent in by committee of deans. However, no revelation was given to indicate the existence of structured strategy evaluation and control process available in extant literature such as setting standards, measurement of achievement, comparing achievement and taking corrective actions where necessary. It can be posited that the college's strategy represented by its programs, projects and budgets were not being measured. The hallmark of what was considered as evaluation and control effort by the school can best be described as being more of documentation possibly to convince government and NCCE of progress made by the college in meeting their respective expectations on formulating and implementing institutional strategic plans.

\section{Strategic Management Practices at Akwa Ibom State Polytechnic, Ikot Osurua \\ During in-depth interviews held with top} management staff of the institution details of strategy formulation, strategy implementation and strategy evaluation and control of the institution were given as follows:

\section{Strategy Formulation}

Members of the SPC were appointed by the Rector. The committee is headed by the Rector. Other members of the committee include, Deputy Rector, Registrar, Head of Works, Head, Department of 
Mechanical Engineering and Dean of Students Affairs. As a body, the committee has never been sponsored to attend a training programme on strategic management except for individual members' exposure to strategic management at various times. Membership of the committee appears limited and stakeholder groups such as students and alumni are not being represented. The committee met and came up with a strategic plan for the institution.

The institution's first attempt at strategic management was in 2013 when it came up with a fiveyear strategic plan to cover the period 2013-2017. This strategic plan was supported with a two-year operational plan. The institution's strategic plan was fashioned to meet requirements for intervention and execution of projects by the Tertiary Education Trust Fund. Further, being a state-owned institution, its policies and programmes are also influenced by the state government.

\section{Strategy Implementation}

Strategy implementation in the institution is centrally co-ordinated. Progress reports on achievement of plans are prepared by the SPC for management's consideration. Allocation of resources to projects and assignment of responsibilities are also carried out by executive management of the institution. Accordingly, budgets and school plan were the tools used in implementation of school plan. However, finance was a major challenge.

\section{Strategy Evaluation and Control}

Strategy evaluation and control in the institution is carried out by the SPC. There was no indication that the institution followed structured strategy evaluation and control process as provided for in extant literature such as setting standards, measurement of achievement, comparing achievement and taking corrective actions where necessary. The interview, further indicated program monitoring was not being consciously carried out to provide feedback that can enhance improvement in the institution's strategic planning effort. Progress reports could only show some activities were on-going perhaps to meet reporting expectations.

\section{Hypothesis Testing}

Table-2: Pearson Correlation Matrix

\begin{tabular}{|l|l|l|l|l|l|}
\hline Variables & LS & OS & OC & RA & SI \\
\hline LS & 1.00 & & & & \\
\hline OS & $-0.337 * *$ & 1.00 & & & \\
\hline OC & $0.357 * *$ & -0.054 & 1.00 & & \\
\hline RA & 0.062 & -0.019 & 0.126 & 1.00 & \\
\hline SI & $0.537 * *$ & $0.382 * *$ & $0.704 * *$ & $0.407 * *$ & 1.00 \\
\hline \multicolumn{7}{|l}{} \\
\hline
\end{tabular}

The Pearson Correlation Matrix in Table 2 shows that there is a strong positive correlation between the organizational issues and strategy implementation. Among the organizational issues influencing strategy implementation, organizational culture had the strongest correlation $(\mathrm{R}=0$.704); leadership followed $(\mathrm{R}=0.537)$; resource allocation $(\mathrm{R}=0.407)$ and organizational structure $(\mathrm{R}=0.382)$. All the correlations were significant at 0.05 level.

Table-3: Results of Multiple Regression Analysis on the influence of Organizational Issues on Strategy Implementation

\begin{tabular}{|l|l|l|l|l|l|}
\hline \multirow{2}{*}{ Model } & \multicolumn{2}{|l|}{ Unstandardized Coefficients } & Standardized Coefficients & \multirow{2}{*}{ Sig. } \\
\cline { 2 - 4 } & B & Std. Error & Beta & & \\
\hline (Constant) & 4.489 & 2.106 & & 2.131 & .037 \\
\hline Leadership & .318 & .098 & .301 & 3.071 & .001 \\
\hline Organ. Structure & .225 & .077 & .213 & 2.766 & .000 \\
\hline Organ. Culture & .402 & .084 & .323 & 3.845 & .012 \\
\hline Resource Allocation & .306 & .096 & .233 & 2.427 & .000 \\
\hline
\end{tabular}

The Multiple Regression Analysis in Table-3 presents the analysis that tested the research hypothesis in the study. The findings indicate that the organizational issues have significant positive influence on strategy implementation in public tertiary institutions of Nigeria at 0.05 level $(\mathrm{t}=0.001, \mathrm{t}=0.000, \mathrm{t}=0.012$, $\mathrm{t}=0.000)$.

Table-4: Model Summary

\begin{tabular}{|l|l|l|l|l|l|}
\hline Model & R & R Square & Adjusted R Square & Std. Error of the Estimate & Durbin-Watson \\
\hline 1 & $.795^{\text {a }}$ & .632 & .600 & .72548 & 1.659 \\
\hline
\end{tabular}


The regression analysis resulted in the model below:

$\mathrm{Y}=4.426+0.318 \mathrm{X} 1+0.225 \mathrm{X} 2+0.402 \mathrm{X} 3+0.306 \mathrm{X} 4$

Where,

\author{
$\mathrm{Y}=$ Strategy Implementation Success in Public \\ Tertiary Institutions \\ $\mathrm{X} 1$ = Leadership \\ $\mathrm{X} 2$ =Organizational Structure \\ $\mathrm{X} 3$ = Organizational Culture \\ X4 = Resources Allocation
}

The regression model above implies that taking named organizational issues, leadership, organizational structure, organizational culture and resource allocation, into account, constant at zero, strategy implementation in public tertiary institutions in Nigeria will be 4.426 . Further, the model indicates that taking named independent variables at zero, a unit increase in leadership will lead to 0.318 increase in strategy implementation in public tertiary institutions in Nigeria; a unit increase in organizational structure will lead to 0.225 increase in strategy implementation; a unit increase in organizational culture will lead to 0.402 increase in strategy implementation and a unit increase in resource allocation will lead to 0.306 increase in strategy implementation. The model also indicates that organizational culture would have the strongest influence on the implementation of strategy in public tertiary institutions of Nigeria.

The model summary above shows that the independent variables are able to explain $63.2 \%$ of strategy implementation in public tertiary institutions in Nigeria; it has a good fit and exhibits a good predictive power. A further implication is that other variables not studied in the current research would contribute $36.8 \%$ to successful strategy implementation in public tertiary institutions in Nigeria.

\section{DISCUSSION OF FINDINGS}

In this study, the strategic management practices of Akwa Ibom State College of Education, Afaha Nsit and Akwa Ibom State Polytechnic, Ikot Osurua were investigated. Result from test of hypothesis indicates that there is a significant positive influence of the independent variables on the dependent variable. In the study, it was established that leadership influenced strategy implementation; this corroborates the studies of Chege, Wachira and Mwenda [6]; Ogbeide and Harrington [27]. The findings also show that organizational structure has significant positive influence on stratey implementation. This is in agreement with Munyoroku [25]; Gituma, Isaiah and Muriithi [13]; Olson, Slater and Hult [28] who reported similar findings in their separate studies. Furthermore, organizational culture indicated a significant positive influence on strategy implementation. This is consistent with the findings of Isaboke [16]; Nawaser, Shahmehr,
Kamel and Vesaln [26]; Salamzadeh, Daraei, and Akbari [32]. The outcome of the study also shows that resource allocation has a significant positive influence on strategy implementation. This supports Kevogo and Waiganjo [20]; Mango [23] who had same results.

\section{CONCLUSION}

The results of this investigation present an insight into strategic management practices of public tertiary institutions in Nigeria and the influence of core organizational issues on strategy implementation in such institutions. Through this study, it has been shown that public tertiary institutions in the country have made various attempts at adopting strategic management in institutional administration. The process of developing educational strategies by these institutions as could be observed from the findings is formal and mainly topdown. However, the application of strategic management by these institutions is characterized by the need to meet the expectations of regulators and funders. The study established the existence of a significant positive relationship of leadership, organizational culture, organizational culture and resource allocation on strategy implementation success in public tertiary institutions in Nigeria, which implies these variables should be given utmost attention for the achievement of successful strategy implementation.

\section{RECOMMENDATIONS}

Based on the findings of this study, the following recommendations are made:

- There is need to strengthen the capacity of administrators of public tertiary institutions in Nigeria through relevant exposure and training in strategic management to broaden their knowledge in the field.

- In view of the significant positive influence of organizational issues, namely leadership, organizational structure, organizational culture and resource allocation on strategy implementation in public tertiary institutions in Nigeria, these variables should be properly managed for strategy implementation success to be achieved.

\section{REFERENCES}

1. Allio, M. K. (2005). A Short, Practical Guide to implementing Strategy. Journal of Business Strategy, 26, 12-21

2. Atieno, R. (2015). Influence of Centralized Structure on Strategy Implementation in the County Government of Nakuru, Kenya International Journal of Economics, Commerce and Management United Kingdom, 3, 5. Avolio, B. J., \& Bass, B. M. (1997). Multifactor Leadership Questionnaire: Manual and Sampler Set, 3rd Ed., Cambridge: Redwood City Ltd. 
3. Bushardt, S. C., Glascoff, D. W., \& Doty D. H. (2011). Organizational Culture, Formal Reward Structure and Effective Strategy Implementation: A Conceptual Model, Journal of Organizational Culture, Communications and Conflict, 15, 57-68.

4. Chandler, A. D. (1962). Strategy and Structure. Cambridge: MA. MITT Press.

5. Charan, R. (2006). Conquering a Culture of Indecision, Havard business Review, 18(6).

6. Chege, A., Wachira, A., \& Mwenda, L. (2015). Effects of Leadership Styles on Implementation of Organization Strategic Plans in Small and Medium Enterprises. Nairobi Management and Administrative Sciences Review, 4, 593-600.

7. Critenden, V. L., \& Critenden, W. F. (2008). Building a capable Organization: The Eight Levers of Strategy Implementation. Business Horizons, 51, 201-209.

8. David, F. R. (2009). Strategic Management: Concepts and Cases, 12 Ed, New York: Prentice Hall.

9. David, F. R. (2011). Strategic Management: Concepts and Cases, $13^{\text {th }}$ Ed., New Jersey: Pearson Education Inc.

10. Federal Republic of Nigeria. (2011). 4-Year Strategic Plan for the Development of the Education Sector. Abuja: Federal Ministry of Education

11. Federal Republic of Nigeria Nigeria. (2004). National Policy on Education. Abuja: Federal Ministry of Education.

12. George Kimiti K., \& Wagoki, A. (2012). Effects of Formal Institutional Structure on Strategic Plan Implementation in Public Secondary Schools in Bahati Sub-County, Kenya. International Journal of Science and Research, 9:16-24.

13. Gituma, I. M. (2012). Effects of Organizational Structure on Strategy Implementation: A survey of Commercial Banks in Kenya. MBA Thesis, Kenyatta University, Kenya.

14. Henry, A. (2008). Understanding Strategic Management. New York: Oxford Press.

15. Hill, J. W., \& Jones, G. (2010). Strategic Management theory. An integrated approach, $3^{\text {rd }}$ Ed. Hoston; Houghton-Mifflin.

16. Isaboke, C. M (2015). Influence of Organization Culture on Strategy Implementation in selected Universities in Kenya. International Journal of Economics, Commerce and Management, United Kingdom, 3, 9-22.

17. Johnson, G., Scholes, K., \& Whittington, R. (2008). Exploring Corporate Strategy: Text and Cases, London: Prentice Hall.

18. Kandie, H. K., \& Koech, A. K. (2015). Factors Influencing Strategy Implementation at the National Treasury Ministry in Kenya. European Journal of Business and Management, 7(10), 1-10.

19. Kazmi, A. (2008). Strategic Management and Business Policy. New Delhi, Tata McGraw-Hill Publishing Company Limited.
20. Kevogo, A. A., \& Waiganjo, E. (2015). Factors Influencing Implementation of Strategic Plans in Public Secondary Schools in Kenya: A Survey of Public Secondary Schools in Thika West SubCounty. The Strategic Journal of Business \& Change Management, 2(2), 1900-1914.

21. Koech, P., \& Namusunge, G. S. (2012). Effect of Leadership Styles on Organization Performance at State Corporation in Kenya. International Journal of Business and Commerce, 21:1-12.

22. Mapetere, D., Mavhiki, S., Nyamwanza, T., Sikomwe, S., \& Mhonde, C. (2012). Strategic role of leadership in strategy implementation in Zimbabwe's state owned enterprises. International Journal of Business and Social Science, 3(16):271276.

23. Mango, D. R. (2014). Determinants of successful strategy implementation: A survey of selected public schools in South Africa. International Journal of Business and Management Invention, 3(1), 41-46.

24. Mehra, A., Smith, B. R., Dixon, A. L., \& Robertson, B. (2006). Distributed leadership in teams: The network of leadership perceptions and team performance. The Leadership Quarterly, 17(3), 232-245.

25. Munyoroku, K. (2012). The Role of Organization Structure on Strategy Implementation among Food Processing Companies in Nairobi. MBA Thesis, School of Business, University Of Nairobi.

26. Nawaser, K., Shahmehr, F. S., Kamel, A., \& Vesal, S. M. (2014). Assessing the Relationship between Strategy and Organizational Culture in an Iranian Manufacturing Industry. Asian Social Science, 10(21), 175.

27. Ogbeide, G. C., \& Harrington, R. (2011). The Relationship among Participative Management Style. International Journal of Management, 50(10), 1-9.

28. Olson, E. M., Slater, S. F., \& Hult, G. T. M. (2005). The importance of structure and process to strategy implementation. Business horizons, 48(1), 47-54.

29. Pearce, J. A., \& Robinson, R. B. (2007). Strategic Management: Strategy Formulation and Implementation. 3rd Ed. London: Richard D. Irwin Inc.

30. Pryor, M. G., Anderson, D., Toombs, L. A., \& Humphreys, J. H. (2007). Strategic implementation as a core competency. Journal of Management Research. South Asia Publication, 17, 4-11.

31. Raps, A. (2009). Implementing Strategy: Tap into the power of four key Factors to deliver Success. Strategic Finance, 12, 49.

32. Ahmadi, A., Ali, S., Salamzadeh, Y., Daraei, M., \& Akbari, J. (2012). Relationship between organizational culture and strategy implementation: Typologies and 
dimensions. Global Business \& Management Research, 4.

33. Schein, E. H. (2010). Organizational Culture and Leadership. $4^{\text {th }}$ Ed. Wiley: Jossey-Bass.

34. Sekaran, U. (2006). Research Methods for Business: a Skill Building Approach. $4^{\text {th }}$ Ed., London: John Wiley and Sons.

35. Thompson, A. A., \& Strickland, A. J. (2003). Strategic Management: Concepts and Cases, 13 Ed., New York: McGraw-Hill/Irwin.

36. Thompson, A. A., Strickland, A. J., \& Gamble, J. E. (2007). Crafting and Executing Strategy: The
Quest for competitive Advantage, Concept and Cases Boston: McGraw-Hill/Irwin.

37. Toma, J. D. (2010). Building Organizational Capacity: Strategic Management in Higher Education (I. Baski). Baltimore: The Johns Hopkins University press.

38. Wheelen, T. L., \& Hunger, J. D. (2006). Strategic Management and Business Policy: Concepts and Cases, $10^{\text {th }}$ Ed., New Jersey: Pearson Prentice Hall.

39. Wheelen, T. L., \& Hunger, J. D. (2008). Strategic Management and Business Policy: Concepts and Cases, $11^{\text {th }}$ Ed., New York: Pearson Prentice Hall. 